\title{
Schwannoma retroperitoneal pélvico
}

\author{
Pelvic retroperitoneal Schwannoma
}

Nelson Muñoz P. ${ }^{1}$, Guillermo Bannura C. ${ }^{1}$, Cristian Gallardo V. ${ }^{1}$ y Diego García P. ${ }^{1}$

Mujer de 77 años, diabética, insuficiencia renal crónica, anticoagulación por fibrilación auricular e IMC: 34. Refiere dolor pélvico de un año de evolución, asociado a parestesia y paresia de la extremidad inferior izquierda, con múltiples consultas previas. La tomografía computada de abdomen y pelvis revela una masa heterogénea de 100 x 67 x
$55 \mathrm{~mm}$, en íntima relación con la estructura ósea y los vasos ilíacos, sin infiltrarlos (Figura 1). La resonancia muestra una lesión expansiva que se extiende hasta el neuroforamen L5-S1 izquierdo de 97 x 56 × $54 \mathrm{~mm}$, adyacente a los vasos ilíacos (Figura 2). Se realiza una resección completa de la lesión, comprobando que desplaza la arteria ilíaca
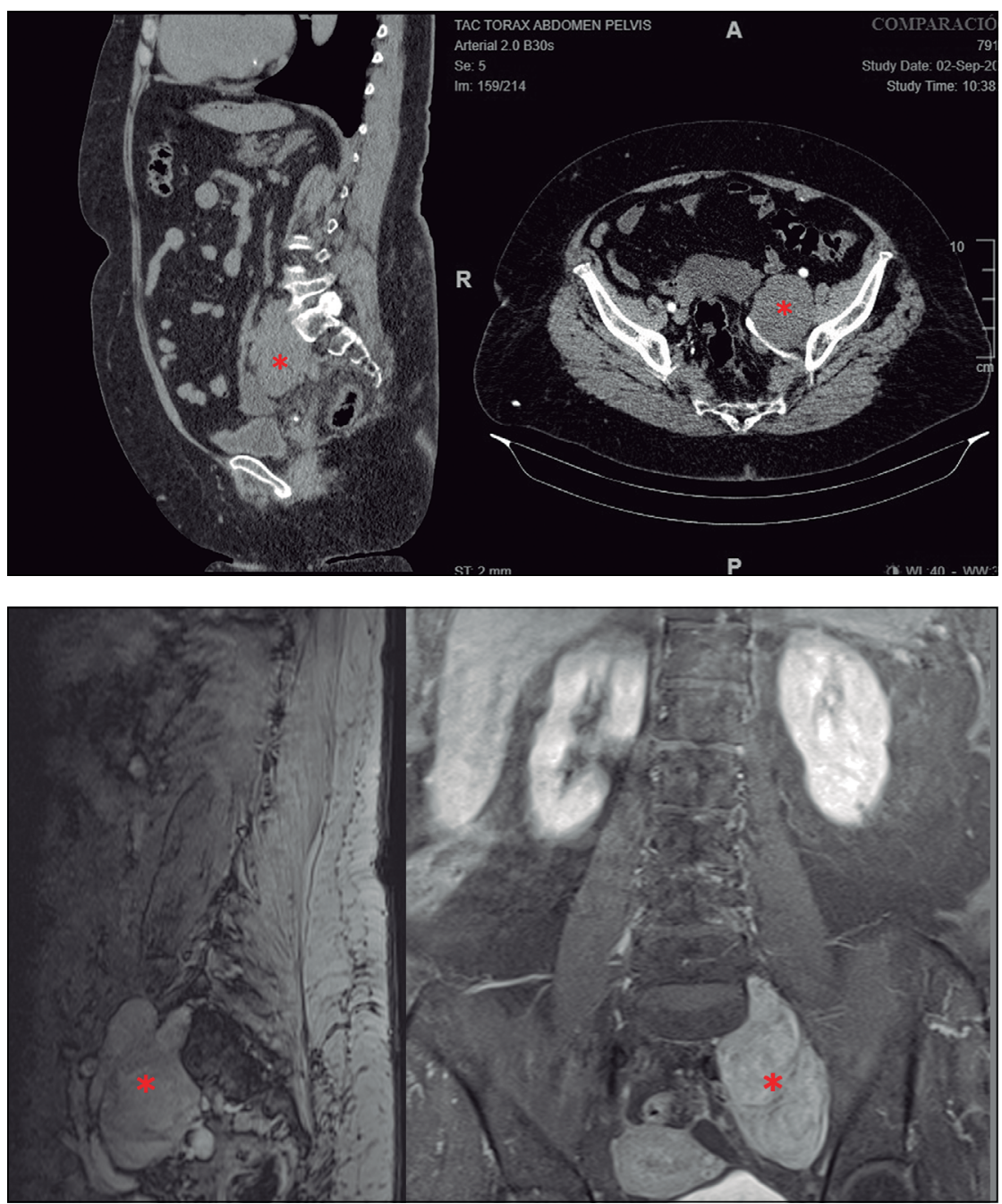

Figura 1. Tomografía computada de abdomen y pelvis.

Figura 2. Resonancia de columna. Cortes sagital (T2) y coronal (T1) con gadolinio.
Servicio y Departamento de Cirugía, Hospital Clínico San Borja Arriarán. Sede Centro, Facultad de Medicina, Universidad de Chile. Santiago, Chile.

Recibido el 15 de mayo de 2020 y aceptado para publicación el 21 de mayo de 2020.

Correspondencia a: Dr. Nelson Muñoz Pérez nelsonmunozperez@gmail. com 


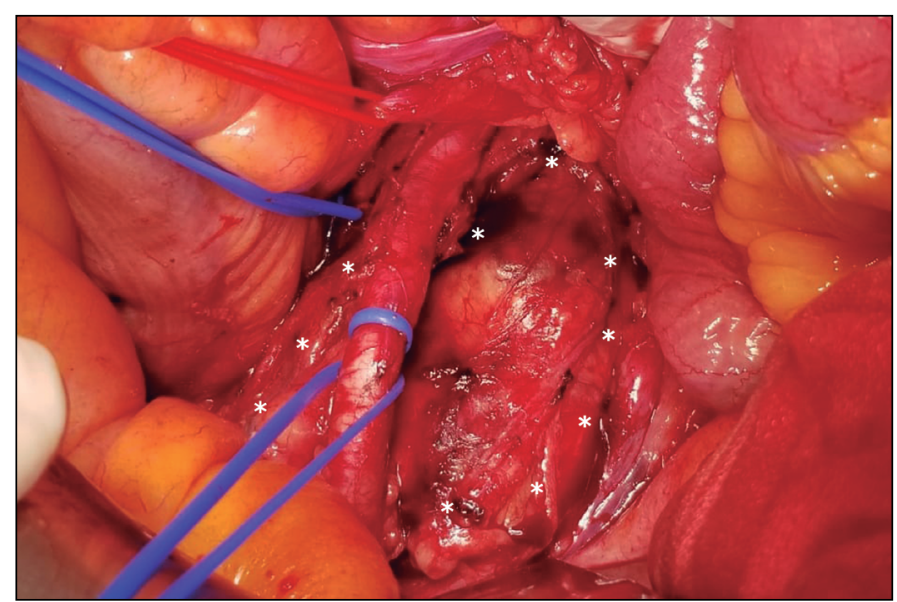

Figura 3. Uréter (cinta roja), arteria hipogástrica izquierda (cinta azul superior), arteria ilíaca externa izquierda (cinta azul inferior), tumor (bordes con asteriscos).

externa izquierda hacia anterolateral y la arteria hipogástrica izquierda y la vena femoral común izquierda a medial, corroborando origen en L5-S1 (Figuras 3 y 4). La histología confirma Schwannoma benigno, con S100 positivo y actina, desmina y calretinina negativos.

Los Schwannomas son tumores mesenquimales de la vaina neural y el $1 \%$ a $3 \%$ tienen una ubicación retroperitoneal ${ }^{1}$. Se consideran tumores benignos de crecimiento lento, no infiltrantes, que presentan síntomas por compresión ${ }^{2}$ con bajo riesgo de malignizar $^{3}$. El diagnóstico imagenológico es inespecífico y la cirugía es la opción terapéutica, ${ }^{4,5}$.

\section{Responsabilidades éticas}

Protección de personas y animales. Los autores declaran que para esta investigación no se han realizado experimentos en seres humanos ni en animales.

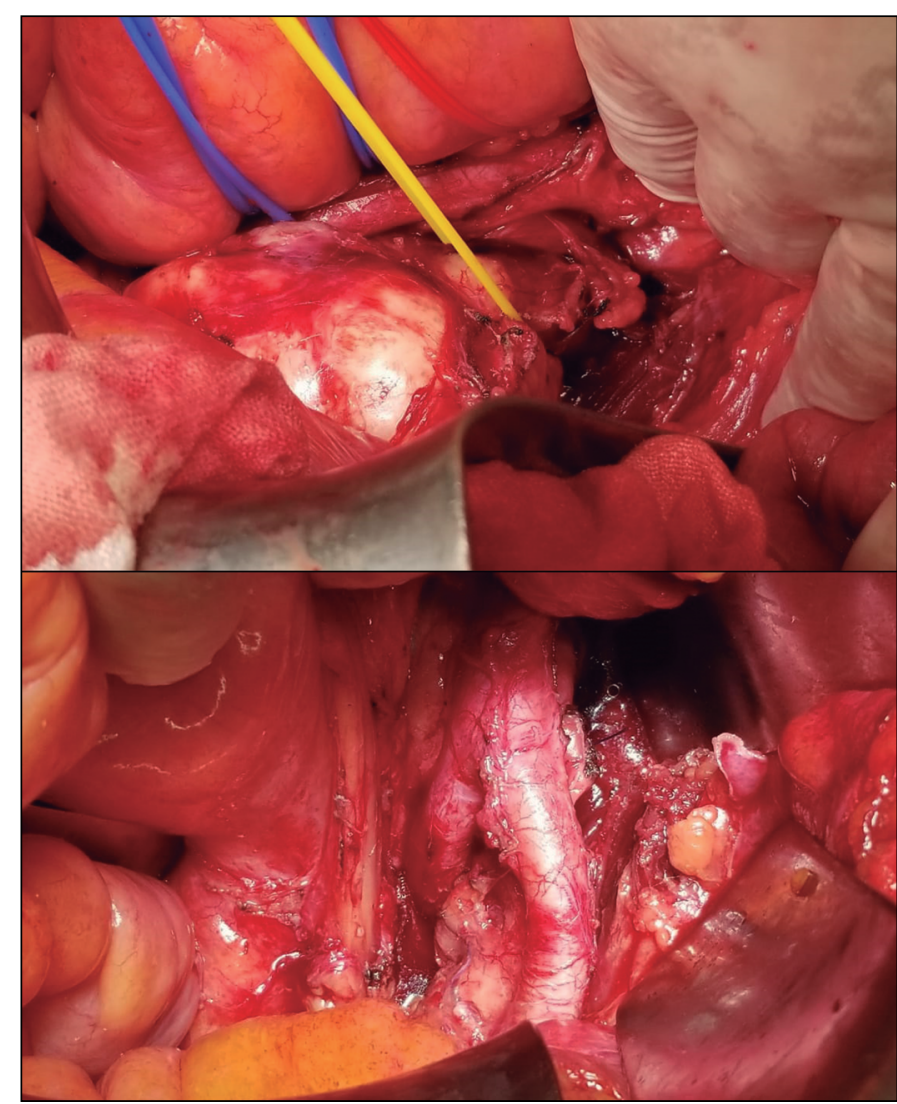

Figura 4. Superior: Pedículo tumoral neuroforamen L5-S1 (cinta vascular amarilla). Inferior: Lecho quirúrgico sin tumor.

Confidencialidad de los datos. Los autores declaran que en este artículo no aparecen datos de pacientes.

Conflictos de interés: no hay.

\section{Bibliografía}

1. Ogose A, Kawashima H, Hatano H, Ariizumi T, Sasaki T, Yamagishi T, et al. The natural history of incidental retroperitoneal schwannomas. PLoS One 2019; 14:8-15.

2. Strauss DC, Qureshi YA, Hayes AJ, Thomas JM. Management of benign retroperitoneal schwannomas:

A single-center experience. Am J Surg. [Internet]. 2011;202:194-8. Available from: http://dx.doi.org/10.1016/j. amjsurg.2010.06.036

3. Lee NJ, Hruban RH, Fishman EK. Abdominal schwannomas: review of imaging findings and pathology. Abdom Radiol. 2017;42:1864-70.
4. Li Q, Gao C, Juzi JT, Hao X. Analysis of 82 cases of retroperitoneal schwannoma. ANZ J Surg. 2007;77:237-40.

5. Mastoraki A, Toska F, Tsiverdis I, Kyriazi M, Tsagkas A, Danias N, et al. Retroperitoneal schwannomas: Dilemmas in diagnostic approach and therapeutic management. J Gastrointest Cancer 2013;44:371-4. 